\title{
ABSENCE OF VISIBLE TOXIC EFFECTS ACCOMPANYING THE SHORT-TERM ADMINISTRATION OF AN AQUEOUS EXTRACT OF ALLIUM SATIVA LINN. IN MALE SPRAGUE-DAWLEY RATS
}

\author{
${ }^{1}$ J. Asiedu-Gyekye Isaac, ${ }^{2}$ Awortwe Charles and ${ }^{3}$ A. Antwi Daniel \\ ${ }^{1}$ Department of Pharmacology and Toxicology, University of Ghana School of Pharmacy, \\ College of Health Sciences, Legon, Ghana \\ ${ }^{2}$ Division of Clinical Pharmacology, Faculty of Health Sciences, \\ University of Stellenbosch, Cape Town, South Africa \\ ${ }^{3}$ Department of Physiology, University of Ghana Medical School, \\ College of Health Sciences, P.O. BOX 4236 Korle-Bu, Ghana
}

Received 2014-01-04; Revised 2014-01-05; Accepted 2014-01-30

\begin{abstract}
Allium sativum is cultivated in the northern part of Ghana and has gained widespread use as chemoprotective, in curing hypertension, impotence and erectile dysfunction. The multipurpose use together with its aphrodisiac activity has resulted in the widespread use of this plant medicine both in meals and as herbal medications. Safety assessment of this plant however is rare. The present study is designed to evaluate the toxic effect of the aqueous extract of Allium sativa on the prostate, heart, liver kidney and haematological parameters after a shorterm administration in male-sprague-dawley rats. The following doses were used in different groups of male Sprague-Dawley Rats: 5000,3000 and $1000 \mathrm{mg} \mathrm{kg}^{-1}$. The following parameters were monitored: Clinical Chemistry, Gross and Histopathology (Heart, kidney, liver and prostate). No death was recorded at the highest dose of $5000 \mathrm{mg} \mathrm{kg}^{-1}$. ASE reduced levels of urea and creatinine but increased levels of liver enzymes ALT, AST, ALP and bilirubin levels as compared to the controls. There was a statistically significant increase in WBC count $(\mathrm{p}<0.005)$ in all the doses except the median dose. There were no significant change in Red Blood Cell count (RBC) ( $<<0.003)$, Haemoglobin (HGB) ( $<<0.03)$, Haematocrit $(\mathrm{HCT}) \mathrm{p}<0.0001)$, Mean Corpuscular Volume (MCV) Other parameters remained relatively unchanged. Gross pathology did not reveal any abnormality. Histopathological analysis showed that the extract did not have any adverse effect on the integrity of these organs. The results were within histopathological limits and did not reveal any abnormality in the examined organs namely: The prostate, kidney, liver and heart which maintained their integrity after the dose administration. Observations were within histopathological limits. ASE is reasonably safe when administered by the oral route within dosages of $1000-5000 \mathrm{mg} \mathrm{kg}^{-1}$ in Sprague dawley rats. This research has provided the safety implications as to the use of this plant.
\end{abstract}

Keywords: Allium sativum, Aphrodisiac, Liver, Prostate, Histopathology, Subacute Toxicity

\section{INTRODUCTION}

Erectile Dysfunction (ED) is normally defined as persistent inability of a man to achieve an erection which is adequate in terms of hardness and duration for satisfactory sexual intercourse (Ratnasooriya and Jayakody, 2006; Suresh et al., 2000; Wannanon et al., 2012). Aphrodisiacs on the other hand are medications that are used to arouse sexual desires or stimulate sexual excitement and enhance sexual performance while Libido

Corresponding Author: J. Asiedu-Gyekye Isaac, Department of Pharmacology and Toxicology, University of Ghana School of Pharmacy, College of Health Sciences, Legon, Ghana Tel: 0208111590 
refers to the sexual urge or the intensity of sexual desires as may be experienced by both sexes (Tajuddin et al., 2005; Ratnasooriya and Dharmasiri, 2000). Herbal preparations have proved to be very beneficial in the management of sexual disorders (Sudwan et al., 2006) probably because they are readily available at minimal or no cost and presumed absence of side effects. For example various plants used for the management of erectile dysfunction and as aphrodisiacs like Moringa oleifera (Prabsattroo et al., 2012), Kaempferia parviflora (Wannanon et al., 2012), (Alpinia calcarata (Ratnasooriya and Jayakodi, 2006), Vanda tessellata (Suresh et al., 2000) and Myristica fragrans (Tajuddin et al., 2005) have been found to be non-toxic in rodents.

Allium sativum (garlic) belongs to the family liliaceae and is used in flavouring soups, stew and as traditional medicine that improves sexual function. In traditional medicine, the bulbs are chewed as anti-snakebite medicine especially when accompanied by oedemma and inflammatory infiltrations (De Sousa et al., 2012). They are also used to cure fever and as anthelminthic. In recent times they have been used widely to treat hypertension, erectile dysfunction, lack of libido and as an aphrodisiac (Dokosi, 1998; Mullaicharam et al., 2004; Guohua et al., 2009). It has also been found to exhibit cardioprotective effects from reperfusion injuries (Bhatti et al., 2008). In fact the aqueous extract of Allium sativum (ASE) produce significant increase in the weight of seminal vesicles, epididymides and sperm count of male animals when compared to controls that had received only the vehicle (Al-Bekairi et al., 1990). Studies have also indicated that garlic can be a protective regimen for lead toxicity (Sharma et al., 2012) and gastroprotection (Amir et al., 2011). Dichloromethane extract of $A$. sativum has been proved to be a potential source of novel acaricidal agent (Nchu et al., 2005).

Mukerji (1953) has reported that oral administration of garlic to children is dangerous and could even be fatal though it has antibacterial effect due to the active principle allicin (Cavallito and Bailey, 1944). According to Zhao et al. (2013), the two main constituent compounds, diallyl trisulfide and diallyl disulfide, exhibited strong acute toxicity against the overwintering $C$. chinensis, with $\mathrm{LC}_{50}$ values of 0.64 and $11.04 \mu \mathrm{g}$ per adult, respectively. The larvicidal effect and principle of Allium sativa has also been extensively conducted and isolated (Amonkar and Banerji, 1971). The multipurpose use together with its aphrodisiac activity has resulted in the widespread use of this plant medicine both in meals and as herbal medications. Use of such products can be very harmful to humans especially where safety data regarding their use is unavailable (Sholikhah et al.,
2014), more so in resource poor communities where orthodox aphrodisiacs are not readily accessible, thus inhabitants fully rely on herbs with known aphrodisiac activity in folklore medicine. Studies on acute toxicity of Allium sativum is however rare. It is against this background that this study is being conducted.

\section{MATERIALS AND METHODS}

\subsection{Collection of Plant Material and Extract Preparation}

Allium sativum bulbs were purchased from the Ghanaian market, cleaned and washed with tap water and a specimen sent to the herbarium at the Ghana Herbarium, University of Ghana for identification and authentification. A specimen was deposited with voucher number IAGSP-AS-1. The cloves of A. sativum were thoroughly ground up and macerated using Sanyo SM (G300) blender (using warm water at $45^{\circ} \mathrm{C}$ for 15 minutes whiles stirring the mixture continuosly to form a liquidised material preparation that was then strained using muslin cloth to remove the solid material $100 \mathrm{~mL}$ of water was added per $100 \mathrm{~g}$ of cloves according to (Gatsing et al., 2003). The solid material was regrounded three times, each time straining using the muslin cloth. extracted using warm water. The powdered samples (freeze-dried material) were stored at $4^{\circ} \mathrm{C}$ and used within seven weeks after production. The yield was $8 \mathrm{~g}$ of extract per $100 \mathrm{~g}$ of cloves.

\subsection{Housing Conditions}

Male Sprague-dawley rats (150g-180g body weight) were purchased from the Centre for Scientific Research into Plant Medicine, Mampong. The rats were housed in plastic cages with stainless steel tops in the animal care facility of the University of Ghana Medical School and kept under standard $12 \mathrm{~h}$ light and $12 \mathrm{~h}$ dark schedule where room temperature, humidity and ventilation were controlled during the acclimatization period of seven (7) days.

Animal feed (AIN-93G Formulation obtained from GAFCO-Ghana) and water were given Ad libitum, but feed was withdrawn $8 \mathrm{~h}$ prior to treatment to ensure effective absorption from the gastrointestinal tract after oral administration. Feed was, however, reintroduced 30 min after treatment. Food was withheld for a further 3-4 $h$ after administration of ASE.

\subsection{Animal Groupings}

The acclimatized rats were randomly placed into four groups (of 7 rats/group), namely a control, low, median and high dose groups. ASE was administered daily via the oral (gavage) route to mimic its use in folklore use-a 
low dose levels (1000 $\mathrm{mg} \mathrm{kg}^{-1}$ ), a high dose (5000 mg $\mathrm{kg}^{-1}$ ) and a control group that received an equivalent volume of the vehicle (distilled water). Freshly prepared solution of ASE was prepared using distilled water.

Animal species used were eight-week old Male Sprague-Dawley Rats (120g-150g body weight). The rats were randomized and each marked in their individual cages for 7 days prior to ASE administration. Equal numbers of animals were used at each dose level of ASE.

\subsection{Sub-acute Toxicity}

A 14 day administration of ASE was conducted in the rats by administering byoral gavage via a stomach tube in accordance with the expected route of administration.

Various doses between 5000 and 3000 and $1000 \mathrm{mg}$ $\mathrm{kg}^{-1}$ were administered after a single high dose of 5,000 $\mathrm{mg} \mathrm{kg}{ }^{-1}$ resulted in no death of the animals. Control animals received only the vehicle.

Three dose levels were administered to the SpragueDawley Rats. The doses administered were as follows:

- Group 1: $5000 \mathrm{mg} \mathrm{kg}^{-1}$ body weight (b.wt)

- Group 2: $3000 \mathrm{mg} \mathrm{kg}^{-1}$

- Group 3: $1000 \mathrm{mg} \mathrm{kg}^{-1}$

- Controls: Vehicle (distilled water) only

The animals were observed individually twice every $30 \mathrm{~min}$, then periodically during the first $24 \mathrm{~h}$ with special attention given to the first four hours to detect any death that might occur with each dosage within $24 \mathrm{~h}$. The rest of the animals were observed daily for 14 days and any clinical signs recorded.

\subsection{Laboratory Examinations}

All the animals had free access to standard laboratory pellet diet (AIN-93G Formulation obtained from GAFCO-Ghana) and water. All experimental procedures and bioassay were conducted in accordance with the internationally acceptable guidelines for evaluating the safety and efficacy of herbal medicines (WHO, 2000; OECD, 2001). The experimental protocol was approved by the Institutional ethical and protocol review committee.

After day fourteen (14), the animals were euthanized by exsanguination under ether anesthesia and blood sampled by cardiac puncture and transferred into EDTA test tubes. An automated haematology analyzer (KX2IN, Sysmex Corporation, Japan) was used to conduct haematological analysis in each blood sample. For biochemical analyses, blood samples from cardiac puncture were collected into plain tubes and centrifuged for $5 \mathrm{~min}$ at $3000 \mathrm{rpm}$. The biochemical assays were performed using SELECTRA JUNIOR VERSION 04 autoanalyzer for biochemical assays (VITAL SCIENTIFIC BV, NETHERLANDS).

Animals were autopsied immediately and all visible organs and tissues were macroscopically examined and harvested. Harvested organs were fixed in $10 \%$ buffered formalin as soon as necropsy was performed. Thus gross necropsy was performed but additionally, selected organs (liver, kidneys, heart and prostate) were examined histologically.

\subsection{Clinical Observations}

The animals were observed throughout the study period. Clinical signs of toxidromes (mydriasis, twitching, salivation, morbidity, piloerection) and mortality were observed after dosing with ASE (Olson et al., 2000). Abnormalities in rate of food and water intake, urine output and behaviour were strictly observed daily.

\subsection{Statistical Analysis}

All data are expressed as means \pm SEM. Data was analysed using analysis of variance (ONE-WAY ANOVA). Level of significance was set at $p<0.05$. Bonferroni multiple comparison post hoc test was performed when $\mathrm{p}<0.05$ and entire data processed using Graphpad prism 5.

\section{RESULTS}

\subsection{Mortality}

No death was recorded at any of the doses administered. The $\mathrm{LD}_{50}$ value therefore was not established.

\subsection{Clinical Signs}

The treated group showed writhing pain upon the vehicle administration over a period of approximately thirty minutes $(30 \mathrm{~min}$ ). This was also observed in the control group but to a much lesser extent. Later on the animals presented with arched-back posture and partially closed eyes with convulsive twitching.

\subsection{Body Weight Changes}

There were reductions in the general body weights of the animals. Although these weight reductions were not significant, it was not observed with the control group.

\subsection{Gross Pathology}

There were no visible pathological changes in the heart, kidney, liver and prostate samples when different doses of ASE were administered to the animals. 
J. Asiedu-Gyekye Isaac et al. / American Journal of Pharmacology and Toxicology 9 (1): 53-67, 2014


(a)
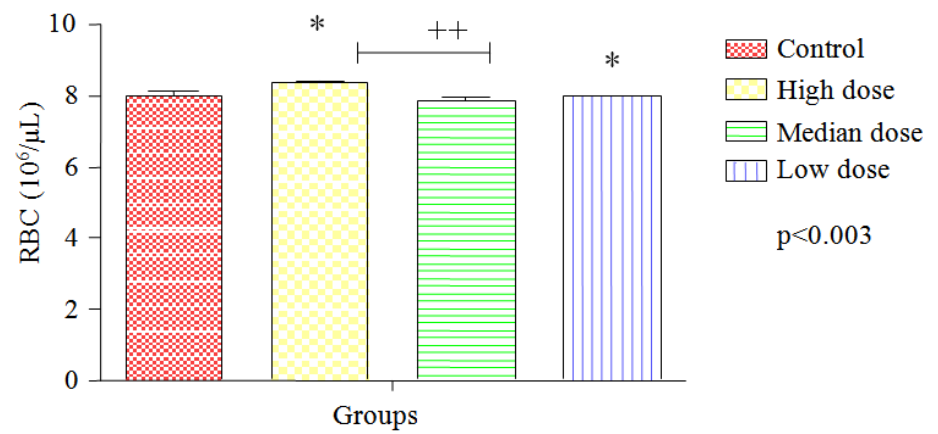

(b)
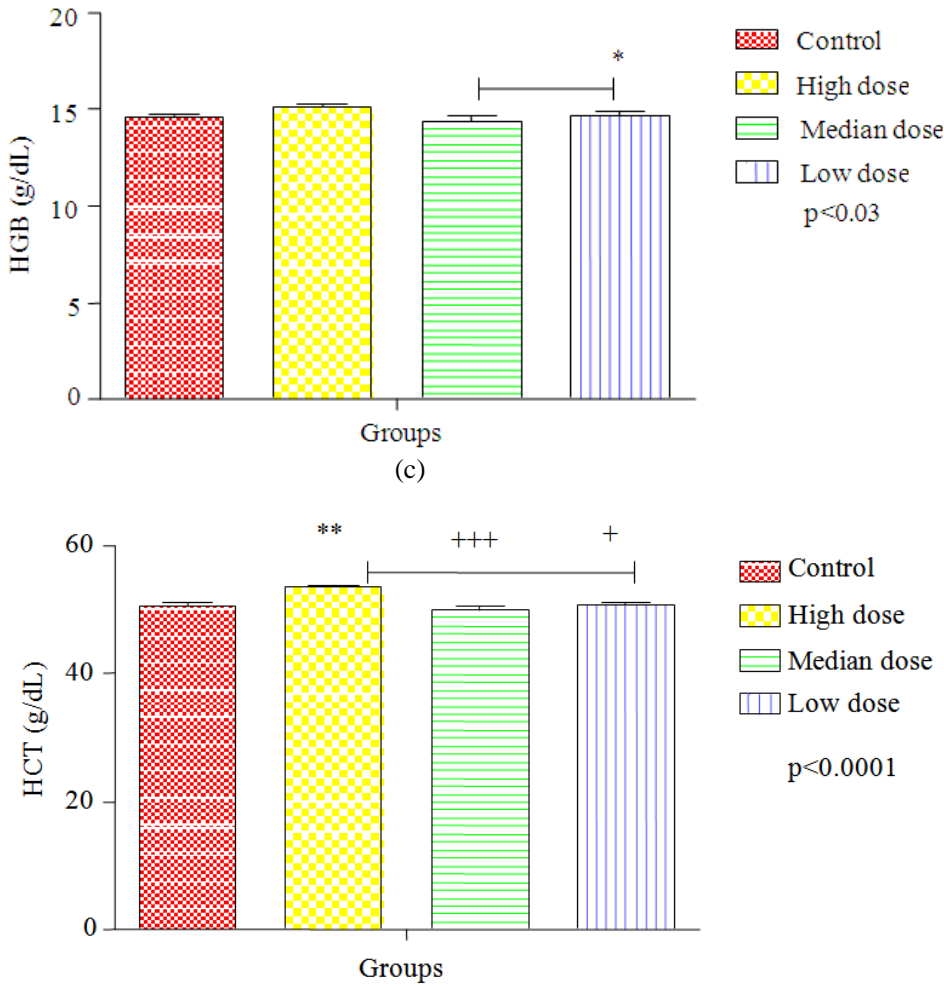

88 Control

$\square$ High dose

$\rightleftarrows$ Median dose

$\square$ Low dose

$\mathrm{p}<0.0001$

(d) 
J. Asiedu-Gyekye Isaac et al. / American Journal of Pharmacology and Toxicology 9 (1): 53-67, 2014

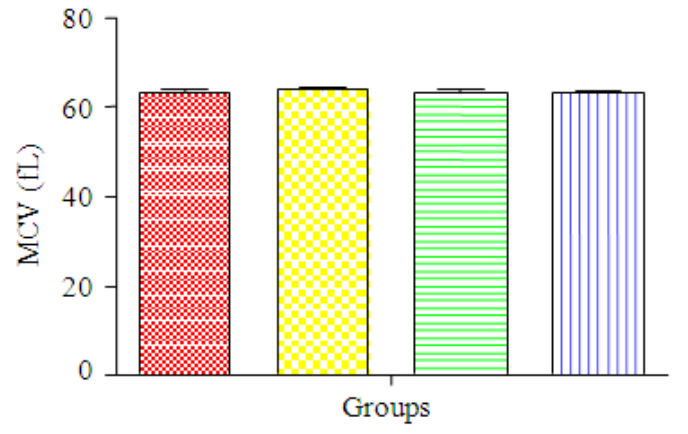

(e)

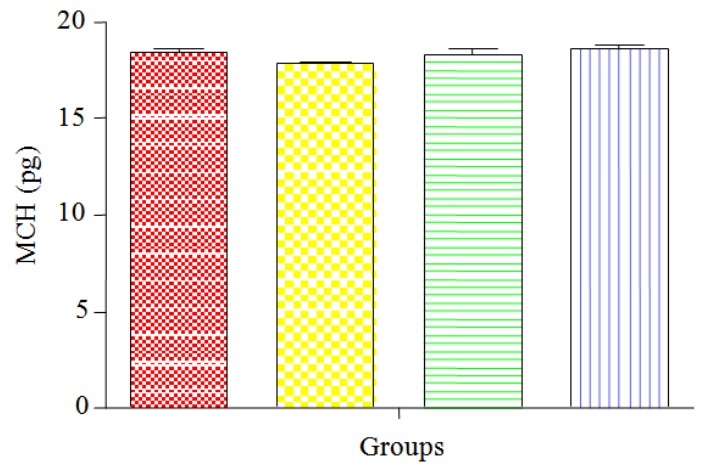

(f)
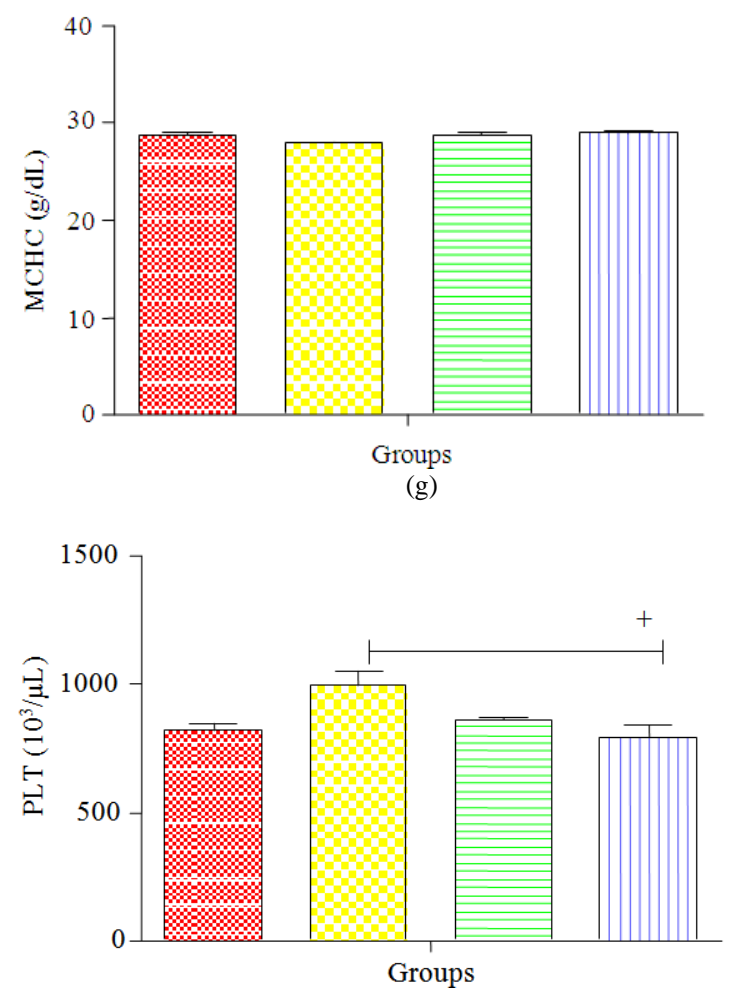

(h)

$$
\begin{aligned}
& \text { Control } \\
& \square \text { High dose } \\
& \square \text { Median dose } \\
& \square \text { Low dose } \\
& \mathrm{p}=0.56
\end{aligned}
$$

Control

$\square$ High dose

$\Xi$ Median dose

$\square$ Low dose

$\mathrm{p}<0.16$
湜 Control

$\square$ High dose

$\square$ Median dose

$\square$ Low dose

$\mathrm{p}<0.02$ \&an Control

$\square$ High dose

$\rightleftarrows$ Median dose

$\square$ Low dose

$\mathrm{p}<0.02$ 
J. Asiedu-Gyekye Isaac et al. / American Journal of Pharmacology and Toxicology 9 (1): 53-67, 2014
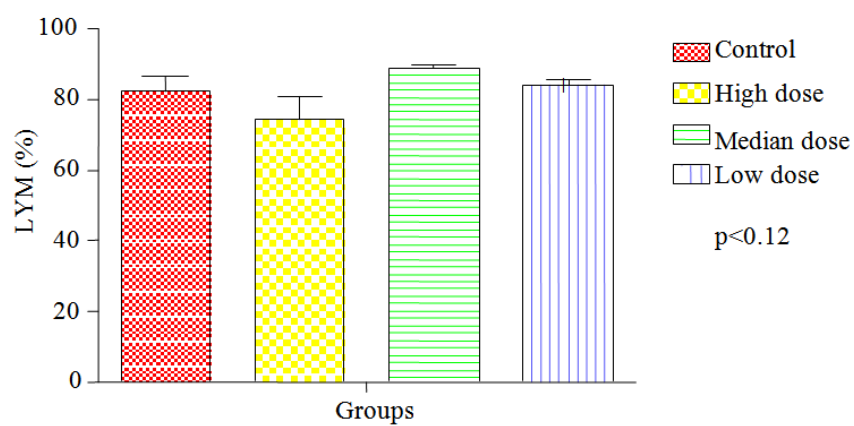

(i)

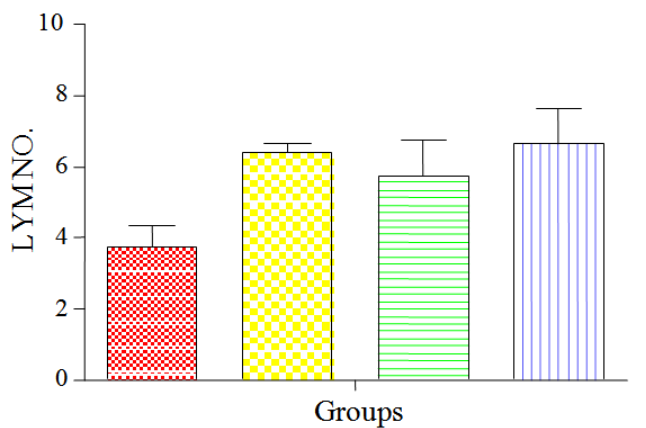

ॠ Control

$\square$ High dose

$\boxminus$ Median dose

$\square$ Low dose

$\mathrm{p}<0.06$

(j)

Fig. 1. Haematological Analysis of a 14-day administration of ASE in male SDRs. Values are expressed as means \pm SEM $(n=7)$. Values of $\mathrm{p}<0.05$ were considered as statistically significant. ${ }^{*} \mathrm{p}<0.05,{ }^{*} \mathrm{p}<0.01$ and $* * * \mathrm{p}<0.0001$ when control was compared with ASE (a) Haematological Analysis of a 14-day administration of ASE in male SDRs. Values are expressed as means $\pm \operatorname{SEM}(n=7)$. Values of $\mathrm{p}<0.05$ were considered as statistically significant. $* \mathrm{p}<0.05, * * \mathrm{p}<0.01$ and $* * * \mathrm{p}<0.0001$ when control was compared with ASE

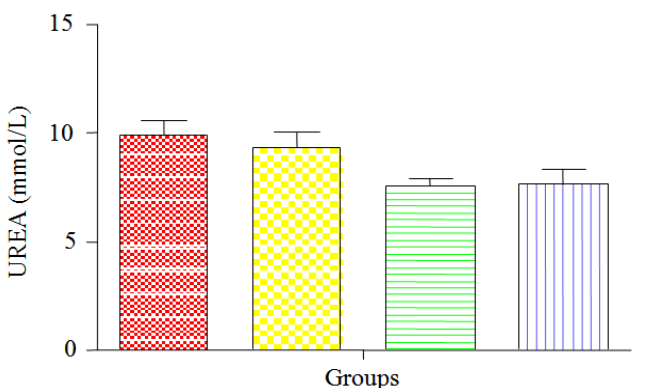

(a)

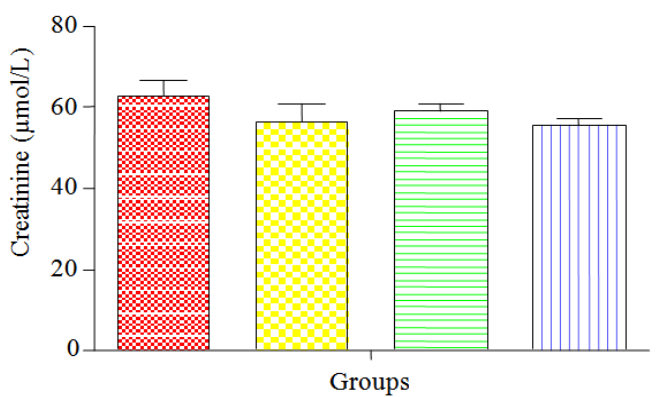

(b)



$8 \times$ Control

\section{$\square$ High dose}

$\rightleftarrows$ Median dose

$\square$ Low dose

$\mathrm{p}<0.43$ 


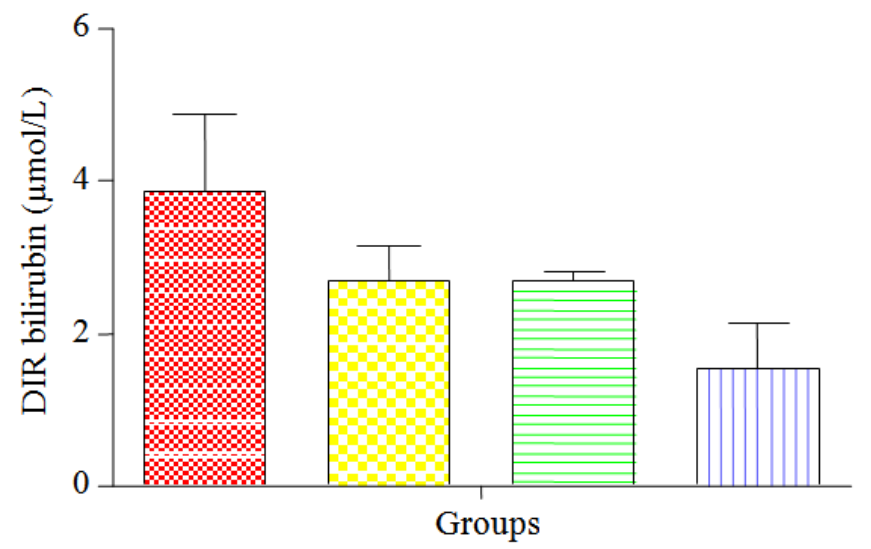

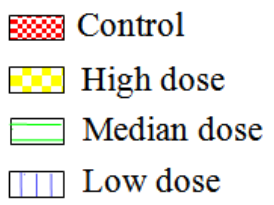

$\mathrm{p}=0.13$

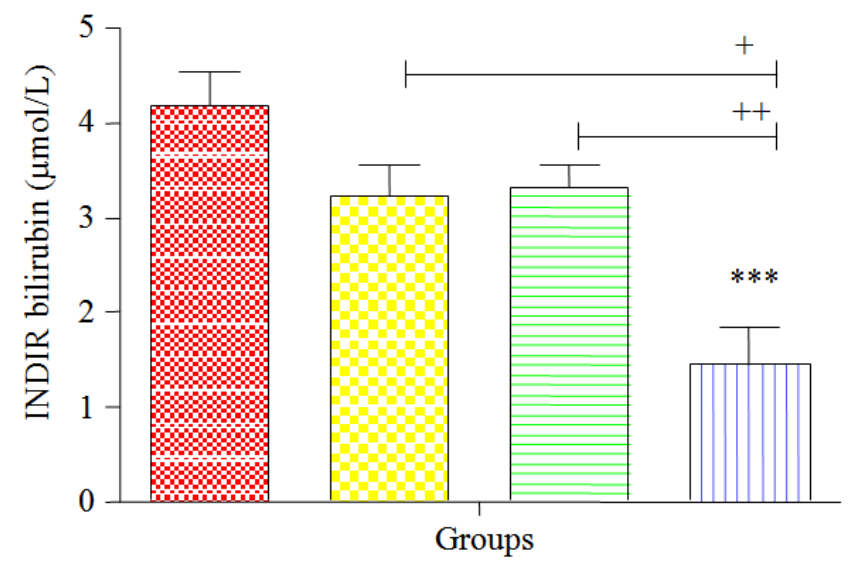

(d)

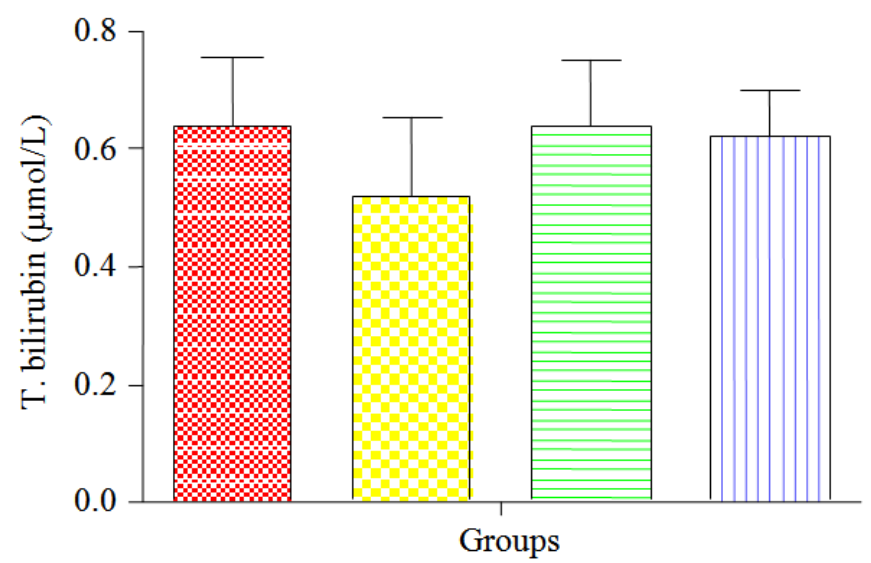

(e)

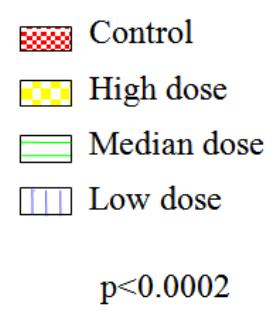

\& Control

$\square$ High dose

Median dose

Low dose

$\mathrm{p}=0.85$

Fig. 2. Biochemical analysis of a 14-day administration of ASE in male SDRs. Values are expressed as means \pm SEM $(n=7)$. Values of $\mathrm{p}<0.05$ were considered as statistically significant. ${ }^{*} \mathrm{p}<0.05$, $* * \mathrm{p}<0.01$ and $* * * \mathrm{p}<0.0001$ when control was compared with ASE. Renal function test 
J. Asiedu-Gyekye Isaac et al. / American Journal of Pharmacology and Toxicology 9 (1): 53-67, 2014

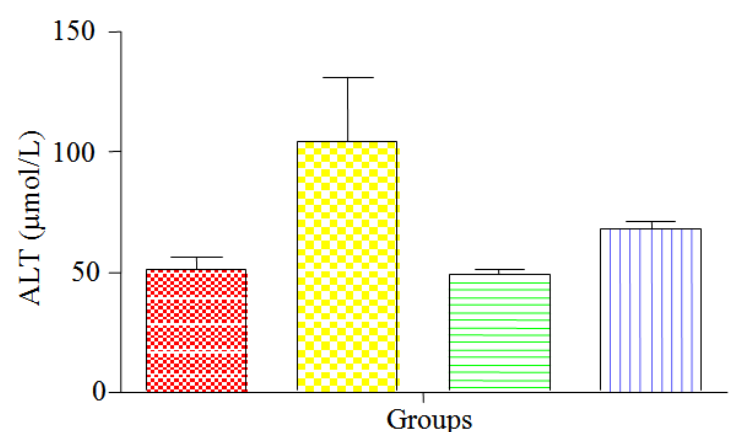

(a)

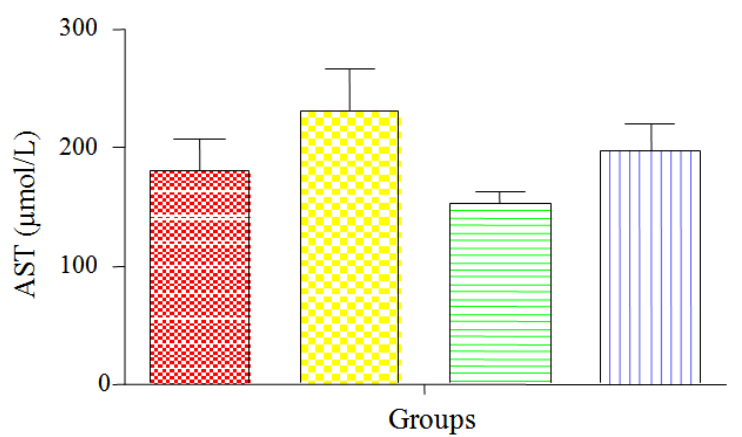

(b)

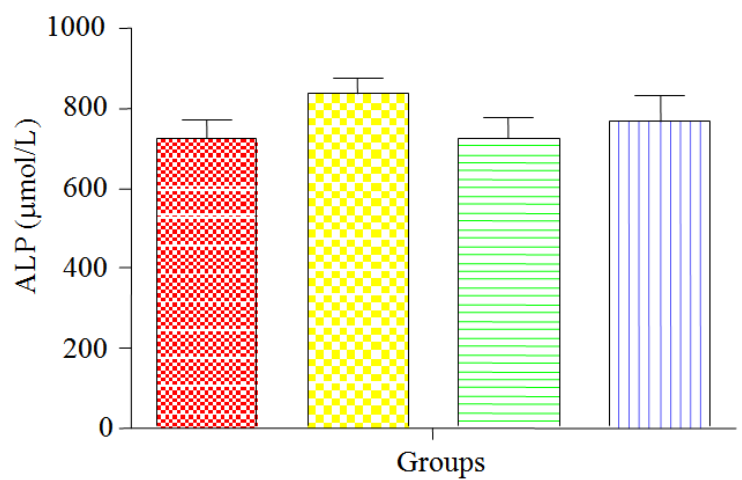

(c)

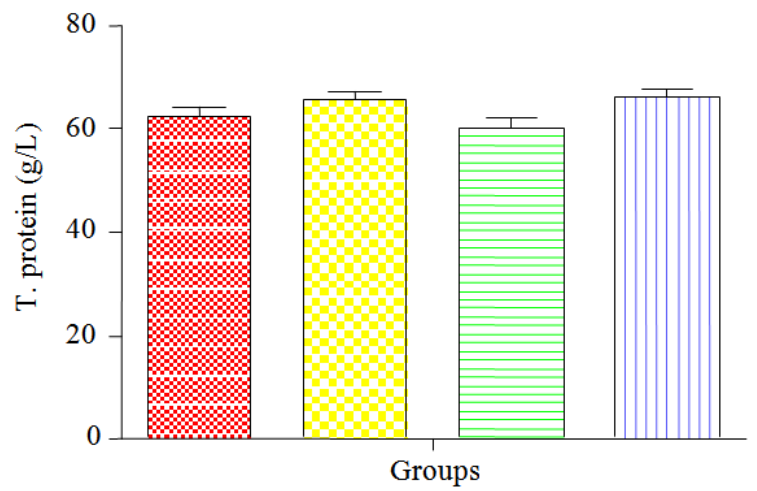

(d)
Control

$\square$ High dose

Median dose

$\square$ Low dose

$\mathrm{p}<0.03$ r Control

$\square$ High dose

$\square$ Median dose

$\square$ Low dose

$\mathrm{p}=0.21$

\section{$8 \times$ Control \\ $\square$ High dose \\ $\square$ Median dose \\ $\square$ Low dose \\ $\mathrm{p}=0.41$}


J. Asiedu-Gyekye Isaac et al. / American Journal of Pharmacology and Toxicology 9 (1): 53-67, 2014



(e)

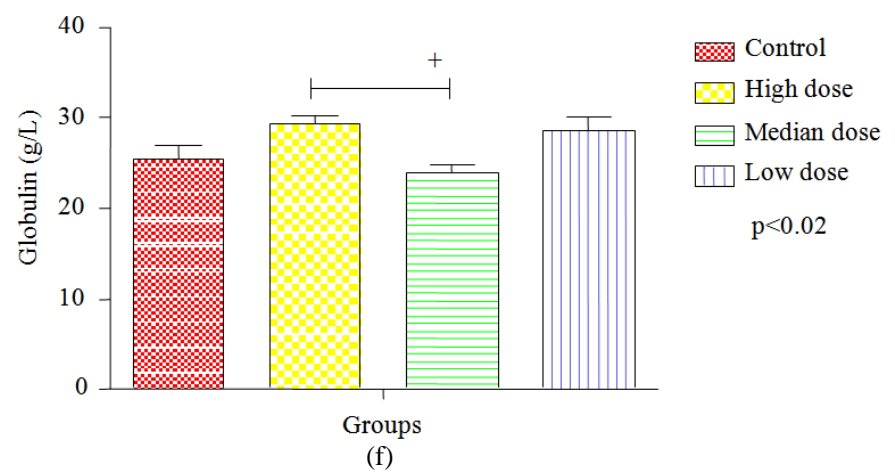

Fig. 3. Liver function tests of a 14-day administration of ASE in male SDRs. Values are expressed as means \pm SEM $(n=7)$. Values of $\mathrm{p}<0.05$ were considered as statistically significant. ${ }^{*} \mathrm{p}<0.05, *{ }^{*} \mathrm{p}<0.01$ and $* * * \mathrm{p}<0.0001$ when control was compared with ASE (a) Haematological Analysis of a 14-day administration of ASE in male SDRs. Values are expressed as means \pm SEM (n $=7$ ). Values of $\mathrm{p}<0.05$ were considered as statistically significant. ${ }^{*} \mathrm{p}<0.05,{ }^{*} \mathrm{p}<0.01$ and $* * * \mathrm{p}<0.0001$ when control was compared with ASE

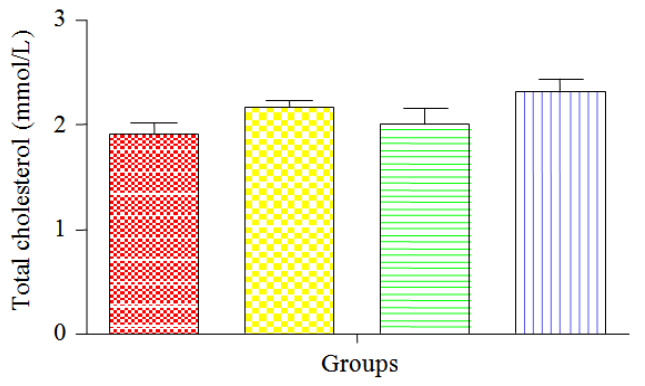

(a)

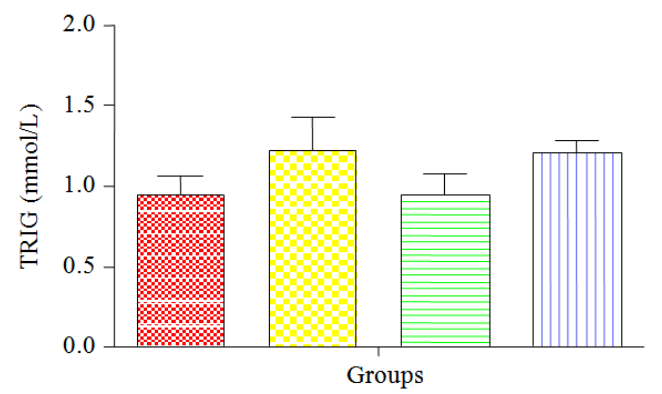

(b)

$$
\begin{aligned}
& \square \text { Control } \\
& \square \text { High dose } \\
& \square \text { Median dose } \\
& \square \text { Low dose } \\
& \mathrm{p}=0.10
\end{aligned}
$$

ntro

$\square$ High dose

$\square$ Median dose

एा Low dose

$\mathrm{p}=0.34$ 


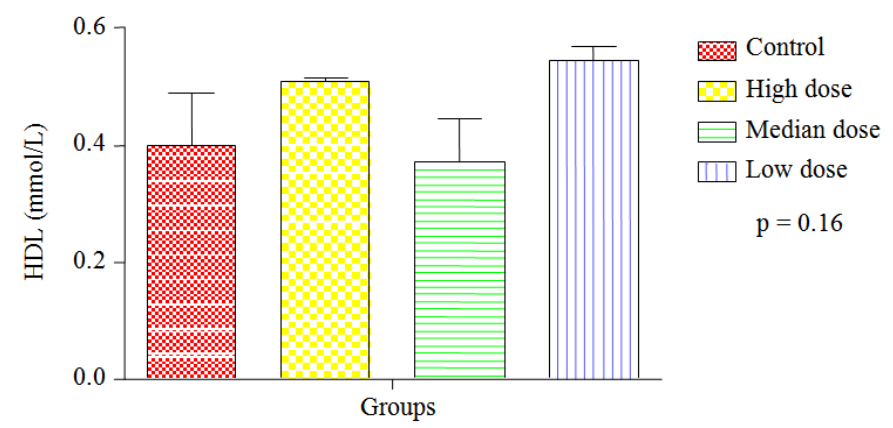

(c)


(d)
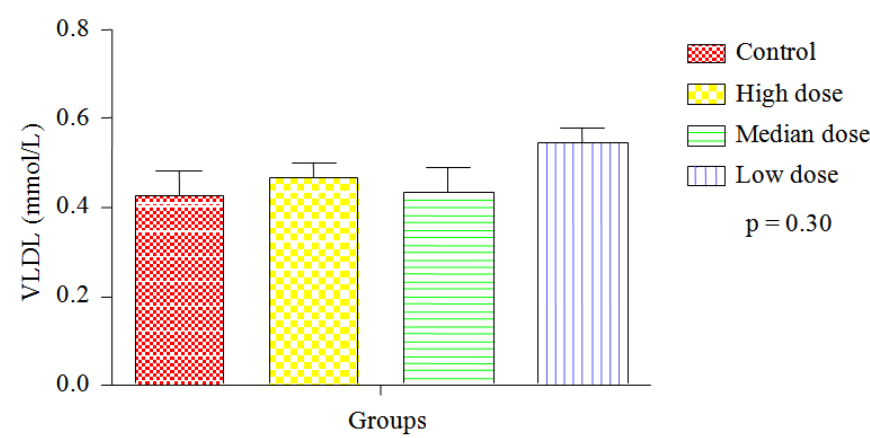

(e)

Fig. 4. Lipid Profile of a 14-day administration of ASE in male SDRs. Values are expressed as means \pm SEM $(n=7)$. Values of $\mathrm{p}<0.05$ were considered as statistically significant. $* \mathrm{p}<0.05$, ${ }^{* *} \mathrm{p}<0.01$ and $* * * \mathrm{p}<0.0001$ when control was compared with ASE (a) Haematological Analysis of a 14-day administration of ASE in male SDRs. Values are expressed as means \pm SEM (n $=7$ ). Values of $\mathrm{p}<0.05$ were considered as statistically significant. $* \mathrm{p}<0.05, * * \mathrm{p}<0.01$ and $* * * \mathrm{p}<0.0001$ when control was compared with ASE

\subsection{Organ Weights}

There were no significant changes in the kidney, liver, lungs, prostate and heart.

\subsection{Blood Chemistry}

These were analysed for dose levels of 5000, 3000 and $1000 \mathrm{mg} \mathrm{kg}^{-1}$ designated as high, medium and low doses respectively.

\subsection{Haematological Studies (Fig. 1)}

There was a statistically significant increase in WBC count, $\mathrm{p}<0.005$ (Fig. 1a) in all the doses except the median dose. There were no significant change in Red Blood Cell count (RBC), $\mathrm{p}<0.003$, (Fig. 1b), Haemoglobin $\mathrm{p}<0.03$, (HGB) (Fig. 1c), Haematocrit (HCT) $\mathrm{p}<0.0001$, (Fig. 1d), Mean Corpuscular Volume (MCV) (Fig. 1e). Mean Corpuscular Hemoglobin 
(MCH) (Fig. 1f, g). $\mathrm{MCH}$ on the average remained relatively unchanged regarding the various doses administered. Platelet Count (Fig. 1h) reduced in the low dose but a considerable increase in the high dose animals compared to the controls. There was a dose dependent reduction in Lymphocytes (LYM) (Fig. 1i) from low to high dose and an increase in Lymphocyte number (LYM NO) (Fig. 1j) at all dose levels.

\subsection{Serum Biochemical Profiles_(Fig. 2)}

There was a decrease in urea (Fig. 2a), Direct Bilirubin (D.BIL) (Fig. 2c), indirect bilirubin (IND. BIL) (Fig. 2d). With regard to total bilirubin (T. BIL) (Fig. 2e), Animals receiving high dose observed a decrease compared to the controls. The median and low dose remained relatively unchanged. There was no significant change in creatinine levels compared to the controls (Fig. 2b).

\subsection{Liver Function Tests (LFTs) (Fig. 3)}

Liver Alanine Transaminase (ALT) (Fig. 3a), Aspartate Transaminase (AST) (Fig. 3b), Alkaline Phosphatase (Fig. 3c), Total Protein (T.P) (Fig. 3d) and globulin (Fig. 3f) recorded high levels especially in the high dose while there was no change in Albumin (ALB) (Fig. 3e) levels.

\subsection{Lipid Profile (Fig. 4)}

With regard to the lipid profile, there was an insignificant increase in total cholesterol (Fig. 4a), Triglycerides (TRIG) (Fig. 4b), High Density Lipoprotein (HDL) (Fig. 4c), low density lipoprotein (LDL) (Fig. 4d) and very low density lipoprotein (VLDL) (Fig. 4e) compared with the controls.

\subsection{Haematological Profile}

\subsubsection{Serum Biochemical Profiles}

3.11.2. Renal Function Test

3.11.3. Liver Function Tests

3.11.4. Lipid Profile

\subsubsection{Serum Biochemical Profiles} 3.11.6. Histopathological Results

All animals were euthanized and various photomicrographs prepared and examined with the sole aim of identifying any with peculiar pathology or abnormalities. Those presented represents photomicrographs with abnormalities if any.

\section{DISCUSSION}

This study has provided a clue to the safety use of the ASE product used as an aphrodisiac and erectile dysfunction in Ghana. The extract proved to be relatively non-toxic at the highest dose of $5,000 \mathrm{mg} \mathrm{kg}^{-1}$.

ALT is the most sensitive marker for liver cell damage. AST and ALP are not specific as ALT in terms of liver damage (Shashi, 2007). The low direct bilirubin levels observed together with the high total bilirubin levels reflects liver cell damage or bile duct damage within the liver itself which might possibly occur at very high doses of ASE administration (Fig. 2c-e). Besides, total protein and albumin levels remained relatively unchanged compared with the controls indicating a possibility of the elevated liver enzymes been caused by a different etiology other than the liver (Arneson and Brickell, 2007). The diagnosis of liver disease depends upon a complete history, complete physical examination and evaluation of liver function tests and further invasive and noninvasive tests. Histopathological results also did not show any histological lesions in the sinusoids and central vein (Fig. 7) of the liver. The results suggests that the liver was in no serious toxic danger from the insult of the herbal preparation (Greaves, 2011).

H\&E stained paraffin sections showed no significant morphological change in the kidneys, liver and heart of both the control and extract-treated rats as evidenced by lack of fatty change or necrosis in the liver. The reduction in creatinine and urea levels by the extract is likely to indicated the absence of adverse effect on the renal system and evidenced by the lack of swelling and proliferation of normally flat endothelial cells lining the glomerular capillaries and also thickening of glomerular basement membrane and proliferation of the endothelial cells investing the outer surface of the glomerular capillary tuft in the kidneys (Corns, 2003; Greaves, 2011). The absence of lesions may suggest that the kidney functions were not compromised. This needs further investigations. The absence of these markers of injury suggests that the extract does not cause structural damage to the liver or the kidneys at the doses used in the present study (Fig. 5-8). The prostate integrity was also not compromised as the histopathological studies revealed lack of acinar distortion and atrophy. Niether was there granulation tissue formation. This is confirmed by other studies that speculate that Allium sativum has no negative effect on the prosta but rather might be beneficial in the management of prostate cancer (Izzo et al., 2004). 


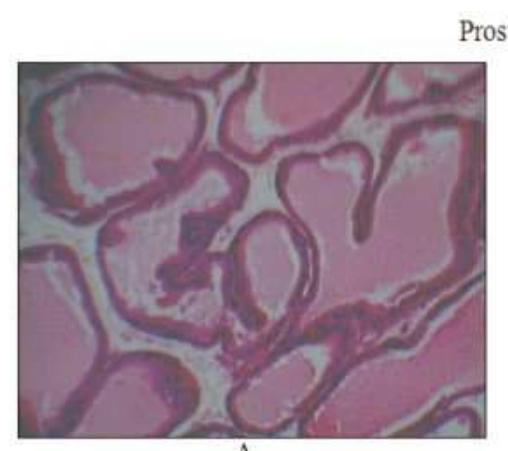

A



C

Prostate

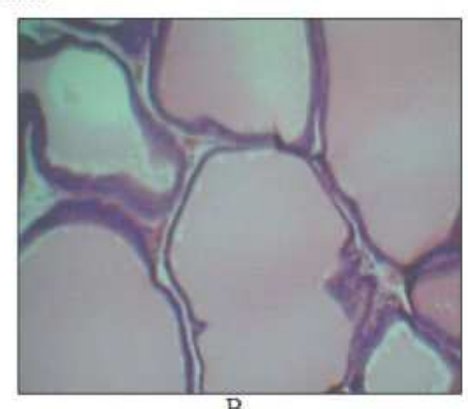

B

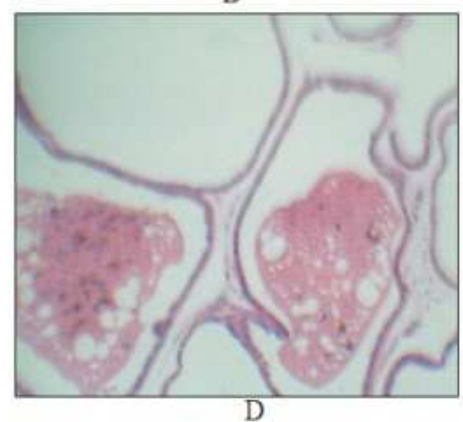

Fig. 5. Photomicrograph of prostate from Male Sprague-Dawley Rats. Comments: No histopathological lesions/abnormalities observed. Lack of acinar distortion and atrophy. No granulation tissue formation

\section{Kidney}

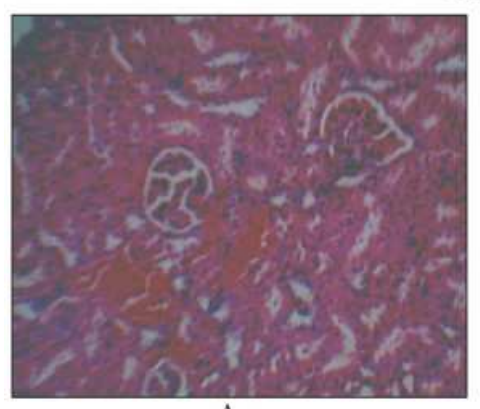

A

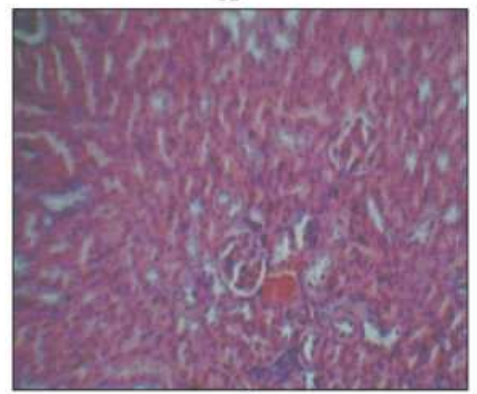

$\mathrm{C}$
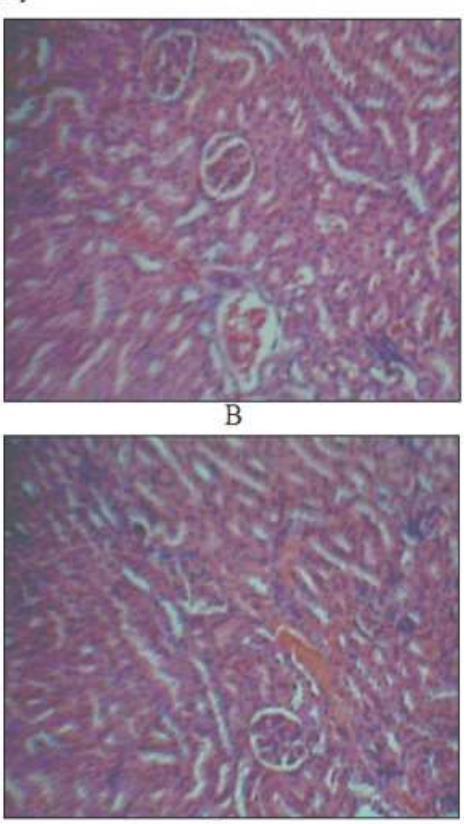

Fig. 6. Photomicrographs of kidney from Male Sprague-Dawley Rats Key: (A) control male, (B) $5000 \mathrm{mg} \mathrm{kg}^{-1}$ bwt treated males, (C) $3000 \mathrm{mg} \mathrm{kg}^{-1}$ bwt treated males and (D) $1000 \mathrm{mg} \mathrm{kg}^{-1}$ treated males, Comments: No observable histological lesions in the glomerulus and tubules of all the groups 
J. Asiedu-Gyekye Isaac et al. / American Journal of Pharmacology and Toxicology 9 (1): 53-67, 2014
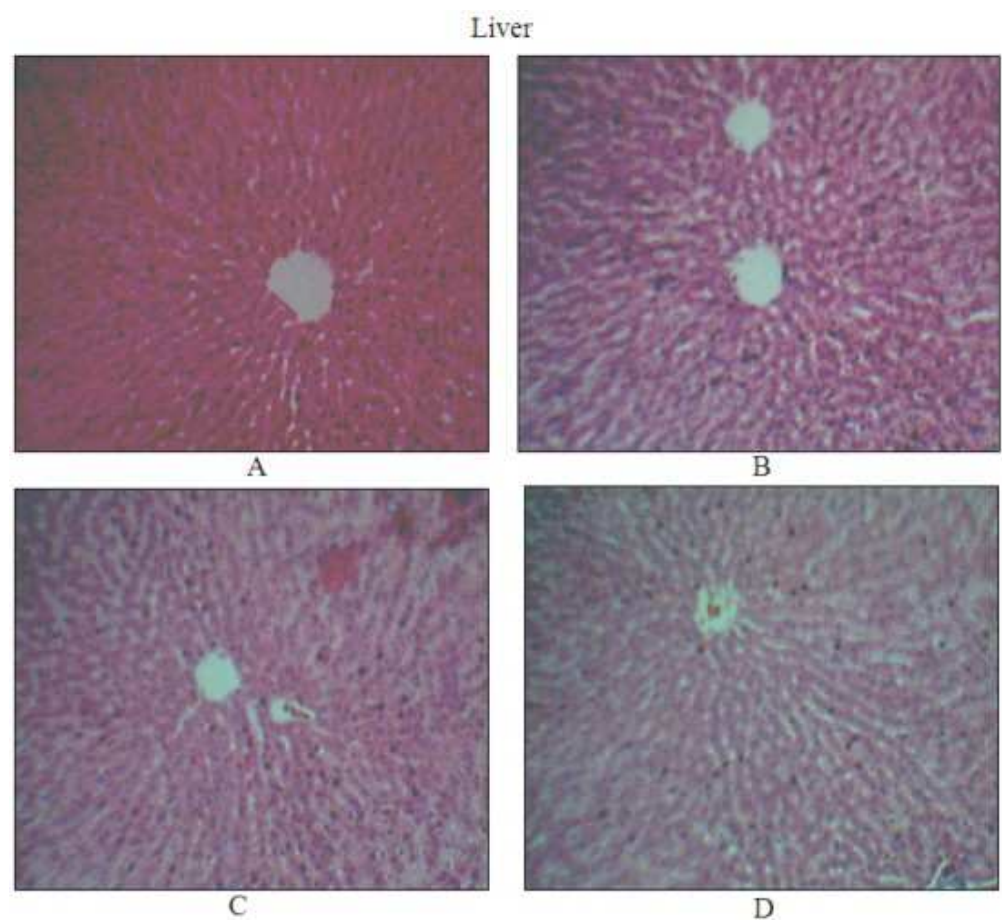

Fig. 7. Photomicrograph of liver from male sprague-dawley rats comments: No noticeable pathological changes in the treated and untreated groups

Heart

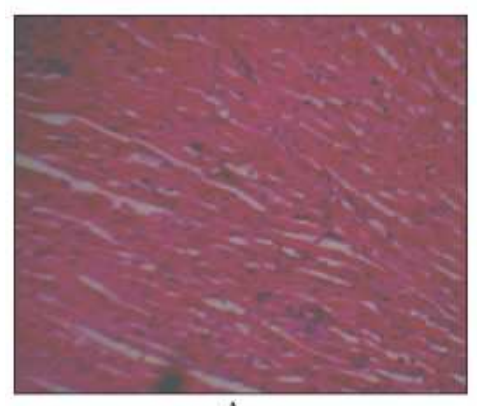

A

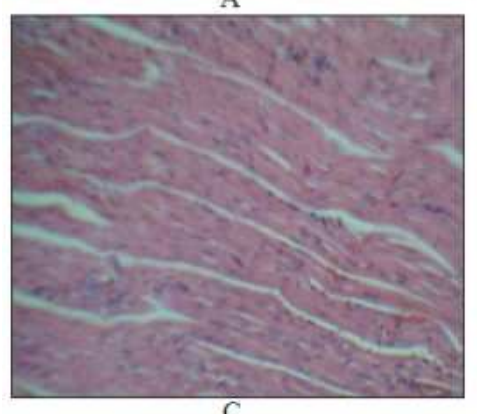

C



B

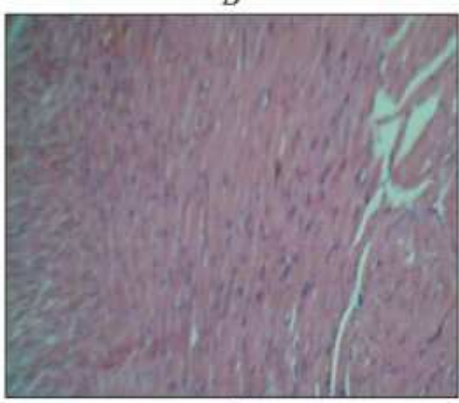

$\mathrm{D}$

Fig. 8. Photomicrographs of cardiac muscle from Male Sprague-Dawley Rats. Comments: No noticeable pathological changes in the treated and untreated groups 
It is rather surprising that various haematological and biochemical parameters of the extract do not proportionally follow a pattern with regards to the high, median and low dose (TTL, 2003). However, reports have been made of a higher dose of Terminalia catapparather $\left(3000 \mathrm{mg} \mathrm{kg}^{-1}\right)$ inhibiting all parameters of sexual behavior rather than the lower dose of $1500 \mathrm{mg}$ $\mathrm{kg}^{-1}$ (Ratnasooriya and Dharmasiri, 2000). The relatively unchanged platelet levels or high platelet levels at high doses $(\mathrm{p}<0.02)$ might suggest the absence of splenomegaly. The results of the blood chemistry carried out in this study is confirmed by other studies where haematological studies revealed an increase in WBC and a decrease in RBC levels of the test animals and absence of splenomegaly (Al-Bekairi et al., 1990; Gatsing et al., 2005).

It will be expedient to assess the effect of this ASE on male hormonal levels though a three-day intraperitonial treatment $\left(500 \mathrm{mg} \mathrm{kg}^{-1}\right.$ ) with the $A$. sativum extract has failed to exhibit any estrogenic or antiestrogenic activity (Al-Bekairi et al., 1990). Isolation and identification of the active constituents could lead to a breakthrough in natural aphrodisiacs.

\section{CONCLUSION}

The $\mathrm{LD}_{50}$ value for ASE was not established. ASE did not produce any visible change in the histopathological examinations of the kidney, lungs, heart and prostate in male Sprague-Dawley rats. The ASE seems to have some beneficiary potential on the renal and cardiovascular system which might need to be confirmed in chronic toxicity studies. ASE is a safe herbal product at the doses used.

A limitation to this research is the absence of reproductive toxicity and evaluation of the Prostate Specific Antigen (PSA). Future research will aim at establishing these parameters in a chronic toxicity study.

\section{ACKNOWLEDGEMENT}

The valuable contribution of Dr. Seidu Mahmood of the Department of Pathology, School of Allied Health Sciences is greatly acknowledged.

\section{REFERENCES}

Al-Bekairi, A.M., A.H. Shah and S. Qureshi, 1990. Effect of Allium sativum on epididymal spermatozoa, estradiol-treated mice and general toxicity. J. Ethnopharmacol., 29: 117-125. DOI: 10.1016/0378-8741(90)90049-Y
Amir, N., A. Al Dhaheri, N. Al Jaberi, F. Al Marzouqi and S.M.A. Bastaki, 2011. Comparative effect of Garlic (Allium sativum), onion (Allium cepa) and black seed (Nigella sativa) on gastric acid secretion and gastric ulcer. Res. Reports Med. Chem., 1: 3-9. DOI: 10.2147/RRMC.S23032

Amonkar, S.V. and S.A. Banerji, 1971. Isolation and characterization of larvicidal principle of garlic. Science, 174: 1343-1344. DOI: 10.1126/science.174.4016.1343

Arneson, W.L. and J.M. Brickell, 2007. Assessment of Liver Function. In: Clinical Chemistry: A Laboratory Perspective. Arneson, W.L. and J.M. Brickell (Eds.), F.A. Davis Davis Company, Philadelphia, ISBN-10: 0803618611, pp: 233-66.

Bhatti, R., K. Singh, M.P.S. Ishar and J. Singh, 2008. The effect of Allium sativum on ischemic preconditioning and ischemia reperfusion induced cardiac injury. Indian J. Pharmacol., 40: 261-265. DOI: $10.4103 / 0253-7613.45152$

Cavallito, C.J. and J.H. Bailey, 1944. Allicin, the antibacterial principle of Allium sativum. I. Isolation, physical properties and antibacterial action. J. Am. Chem. Soc., 66: 1950-1951. DOI: 10.1021/ja01239a048

Corns, C.M., 2003. Herbal remedies and clinical biochemistry. Ann. Clin. Biochem., 40: 489-507. DOI: $10.1258 / 000456303322326407$

De Sousa, E.A., J.A.H.M. Bittencourt, N.K.S. De Oliveira, S.V.C. Henriques and L.C.D.S. PicanÃßo et al., 2012. Influence of a low-level semiconductor gallium arsenate laser in experimental envenomation induced by Bothrops atrox snake venom. Am. J. Pharmacol. Toxicol., 7: 141-148. DOI: 10.3844/ajptsp.2012.141.148

Dokosi, O.B., 1998. Herbs of Ghana. 1st Edn., Ghana Universities Press, Accra, ISBN-10: 9964302169, pp: 746.

Gatsing, D., R. Aliyu, J.R. Kuiate, I.H. Garba and K.H. Jaryum et al., 2005. Toxicological evaluation of the aqueous extract of Allium sativum bulbs on laboratory mice and rats. Cameroun J. Exp. Biol., 1: 39-45. DOI: 10.4314\%2Fcajeb.v1i1.37926

Gatsing, D., R. Aliyu, W.B. Meli, G.I. Adoga and M.F. Tchouanguep, 2003. Phytochemical profile and antisalmonellal properties of Allium sativum bulb extract. West Afr. J. Biol. Sci., 14: 29-36. 
Greaves, P., 2011. Histopathology of Preclinical Toxicity Studies: Interpretation and Relevance in Drug Safety Evaluation. 4th Edn., Academic Press, New York, ISBN-10: 0444538615, pp: 892.

Guohua, H., L. Yanhua, M. Rengang, W. Dongzhi and M. Zhengzhi et al., 2009. Aphrodisiac properties of Allium tuberosum seeds extract. J. Ethnopharmacol., 122: 579-582. DOI: 10.1016/j.jep.2009.01.018

Izzo, A.A., R. Capasso and F. Capasso, 2004. Eating garlic and onion: A matter of life or death. Br. J. Cancer, 91: 194-194. DOI: 10.1038/sj.bjc.6601918

Mukerji, B., 1953. The Indian Pharmaceutical Codex, vol. I: Indigenous drugs. J. Sci. Indus., Res.

Mullaicharam, A.R., B. Karthikeyan and R. Umamaheswari, 2004. Aphrodisiac property of Allium sativum Linn. extract in male rat. Hamdard Medicus, 47: 30-35.

Nchu, F, S.R. Magano and J.N. Eloff, 2005. In vitro investigation of the toxic effects of extracts of Allium sativum bulbs on adults of Hyalomma marginatum rufipes and Rhipicephalus pulchellus. J. S Afr. Vet. Assoc., 76: 99-103. DOI: 10.4102/jsava.v76i2.405

OECD, 2001. Guidelines: OECD Guidelines for Testing of Chemicals: Acute Oral Toxicity-fixed Dose Procedure.

Olson, H., G. Betton, D. Robinsdon and K. Thomas, 2000. Concordance of toxicity of Pharmaceuticals in humans and in animals. Regul. Toxicol Pharmacol., 32: 56-67. DOI: 10.1006/rtph.2000.1399

Prabsattroo, T., J. Wattanathorn, S. Iamsa-ard, S. Muchimapura and W. Thukhammee, 2012. Moringa oleifera leaves extract attenuates male sexual dysfunction. Am. J. Neurosci., 3: 17-24. DOI: 10.3844/amjnsp.2012.17.24

Ratnasooriya, W.D and M.G. Dharmasiri, 2000. Effects of Terminalia catappa seeds on sexual behaviour and fertility of male rats. Asian J. Androl., 2: 213219. PMID: 11225980

Ratnasooriya, W.D. and J.R. Jayakody, 2006. Effects of aqueous extract of Alpinia calcarata rhizomes on reproductive competence of male rats. Acta Biol. Hung, 57: 23-35. DOI: 10.1556/ABiol.57.2006.1.3

Sharma, V., A. Sharma and L. Kansa, 2012. The effect of oral administration of Allium sativum extracts on lead nitrate induced toxicity in male mice. Food Chem. Toxicol., 48: 928-36. DOI: 10.1016/j.fct.2010.01.002. Epub 2010 Jan 12
Shashi, K.R., 2007. A toxicologist guide to the diagnostic interpretation of hepatic biochemical parameters. Food Chem. Toxicol., 45: 1551-1557. DOI: 10.1016/j.fct.2007.06.007

Sholikhah, E.N., M.A. Wijayanti and Mustofa, 2014. In vivo antiplasmodial activity and acute toxicity of standardized extract of Eurycoma longifolia Jack. Root traditionally used to treat Malaria. Am. J. Pharmacol. Toxicol., 9: 24-28. DOI: 10.3844/ajptsp.2014.24.28

Sudwan, P., K. Saenphet, S. Saenphet and S. Suwansiriku, 2006. Effect of Kaempferia parviflora Wall. ex. Baker on sexual activity of male rats and its toxicity. Southeast Asian J. Trop Med. Public Health, 3: 210-215. PMID: 17547083

Suresh, K.P.K., A. Subramoniam and P. Pushpangadan, 2000. Aphrodisiac activity of Vanda tessellata (Roxb.) Hook.Ex Don extract in male mice. Ind. J. Pharmacol., 32: 300-304.

Tajuddin, A.S., A. Latif, I.A. Qasmi and K.M.Y. Amin, 2005. An experimental study of sexual Function improving effect of Myristica fragrans Houtt. (Nutmeg). BMC Complement Altern Med., 5: 16. DOI: $10.1186 / 1472-6882-5-16$

TTL, 2003. Hematological Clinical Chemistry values Sprague Dawley rats.

Wannanon, P., J. Wattanathorn, T. Tong-Un, P. Pangphukiew and S. Muchimapura et al., 2012. Efficacy assessment of Kaempferia parviflora for the management of erectile dysfunction. OnLine J. Biol. Sci., 12: 149-155. DOI: 10.3844/ojbsci.2012.149.155

WHO, 2000. General Guidelines for Methodologies on Research and Evaluation of Traditional Medicine. 1st Edn., World Health Organization, Geneva, ISBN-10: 0119869357, pp: 71.

Zhao, N.N., H. Zhang, C. Zhang, X. Xiao and B.L. Zhou et al., 2013. Evaluation of acute toxicity of essential oil of garlic (Allium sativum) and its selected major constituent compounds against overwintering Cacopsylla chinensis (hemiptera: Psyllidae). J. Econ. Entomol., 106: 1349-1354. DOI: 10.1603/EC12191 